\title{
Correction to: Enchantment and Enhancement in the Land of the Merlion, by Pock AR. Med Acupunct 2018;30(3):126-129. DOI: 10.1089/acu.2018.29083.arp
}

\footnotetext{
T THE JUNE 2018 issue of Medical Acupuncture (volume 30, number 3, pp. 126-129), the article entitled Enchantment and Enhancement in the Land of the Merlion by Arnyce R. Pock requires correction.

\begin{abstract}
On page 128, we would like to acknowledge that while Dr. Daniel Asis was the first author on the paper describing the use of auricular chromotherapy for the treatment of psychological trauma, it was Dr. Alexandre Yoshizumi who presented the workshop on this topic during the Ninth International Symposium on Auriculotherapy, held in Singapore, August 10-12, 2017.
\end{abstract}

The online version of the article has been corrected to reflect this change.

The author regrets this error. 